\title{
The roots of evolutionary economics: Crisis, transformation and metamorphosis
}

\author{
Milan Zeleny ${ }^{\mathrm{a}, \mathrm{b}, *}$ \\ ${ }^{a}$ Fordham University, New York, USA \\ ${ }^{\mathrm{b}}$ The Tomas Bata University, Zlín, Czech Republic
}

\begin{abstract}
Most world economies are undergoing fundamental transformations of economic sectors, shifting their employed workforce through the secular sequence of $(1$. Agriculture $\longrightarrow 2$. Industry $\longrightarrow 3$. Services $\longrightarrow 4$. Government). The productivity growth rate is the driving force. Most advanced economies have reached the final stages of the sequence. Assorted recessions, crises and stagnations are simply cofluent, accompanying phenomena. Crises might be cyclical, but economic evolution is unidirectional. Traditional economics can hardly distinguish phenomena of crisis from those of the transformation. Because there is no "fifth sector", some economies are entering the phase of metamorphosis, for the first time in history. Metamorphosis is manifested through deglobalization, relocalization and autonomization of local and regional economies. We are entering the Age of Entrepreneurship.
\end{abstract}

Keywords: Evolutionary economics, entrepreneurship

\section{Introduction}

Since 2007, all advanced economies (especially USA, Japan and Western Europe) are experiencing recession, anemic growth and secular stagnation. It is remarkable that virtually no causal diagnosis has been attempted; the notion of cyclical crisis prevails and consequently also the month-to-month and year-toyear serial optimism - with no theoretical or empirical foundations. So called "policy" has shrinked into nothing more than "closely monitoring" the data and, from time to time, manipulating interest rates, printing money, getting further into debt and engaging in economic wars through increasingly dysfunctional "sanctions".

The government, anywhere, cannot substitute (being increasingly in debt) for private business, entrepreneurial and innovation activities. The four sectors represent the end of an era: there is no fifth sector. The advanced economies are not undergoing cyclical crises, but experiencing secular and

${ }^{*}$ Corresponding author: Milan Zeleny, Fordham University, New York, USA; The Tomas Bata University, Zlín, Czech Republic. E-mail: mzeleny@ fordham.edu. irreversible transformation to the new regime (or new normal) which qualitatively changes the way of economic life of mankind as well of the ways of production and consumption.

Chinese premier Li proposed "mass entrepreneurship and innovation" for the new-normal China. Such initiatives will resonate with many transforming economies. An international foundation is currently being established (see http://milanzeleny.com/enUS/pages/1/-/75/162/czech-chinese-american-found ation). Mass entrepreneurship must be supported by a network of entrepreneurial universities, where entrepreneurship would be taught and practiced, not just by reading books, but through real-life establishment and operation of innovative companies and firms; i.e., through creating real entrepreneurial knowledge (not just information). Entrepreneurial University teaches entrepreneurship through action, not just through description of action. We are rapidly moving from the information era to the times of real knowledge, from talking to doing, from descriptions to actions.

Transformations of economic sectors, like 1. agriculture $\longrightarrow 2$. industry $\longrightarrow 3$. services $\longrightarrow 4$. state, have reached their final stages with no turning 
back. The government, anywhere, cannot substitute (being increasingly in debt) for private business, entrepreneurial and innovation activities. We are entering the Age of Entrepreneurship. The four sectors represent the end of an era: there is no fifth sector. The advanced economies are not undergoing cyclical crisis, but experiencing secular and irreversible transformation to the new regime (or new normal) which qualitatively changes the way of economic life of mankind as well of the ways of production and consumption. For further details of this model of Evolutionary economics, see for example http://en. wikipedia.org/wiki/Transformation_in_economics.

Mass entrepreneurship is already a part of the new metamorphosis. After a long string of transformations, there is a newly emerging economy, characterized by the processes of deglobalization, relocalization and regionalization. It is akin to biological metamorphosis: after many stages of caterpillar development, there emerges a butterfly - quite different and much more beautiful, yet still an integral part of the same organism. Metamorphosis captures the qualitative character and irreversibility of the "new normal". Accompanying or derived "transformations" of metamorphosis are, for example, self-service, disintermediation, mass customization, reintegration of labor, task and knowledge, digitization, circular organization, waste-less business and tradeoffs-free optimization.

It is now time to shift from the traditional view of economy as a machine to its new understanding as an adaptive, learning and autonomous social organism. It is time to move from the mechanistic to "living" evolutionary economics. The regional dimension of ongoing metamorphosis requires active and integrated cooperation of the crucial regional and local Triad: 1 . business and companies; 2 . entrepreneurial schools and universities; 3 . political self-government. This Triad leads to regional and local efforts towards innovative growth, action-based learning, and social harmony and autonomy.

In the post-crisis age of transformation and metamorphosis, in the age of entrepreneurship, the strategy of business, education and politics must be three-prong: 1. Understand the change, what and why; 2 . Adapt to the change because it is natural, evolutionary and spontaneous; 3 . Discover and exploit new opportunities for business, learning and individual and social life enhancement.

To these ends, an international ZET foundation for the age of entrepreneurship has been established and will be introduced at the CASA conference in Prague.

\section{Secular stagnation}

The term "secular stagnation" is a rather poor designation of a long period of below-trend economic growth, including no growth at all. It seems to be proposed and supported by Larry Summers, while opposed by Ben Bernanke as being only temporary. Classifying such politically opposing views as pessimistic or optimistic is rather simplistic: faith and personal beliefs or convictions should be irrelevant in economic reasoning.

Summers at least, defines "secular stagnation", tautologically, as a chronic excess of savings over investment. This kind of disequilibrium pushes down the interest rates naturally, reinforcing policy rates of the US Fed to set the rates close to zero ("as economic conditions demand") via quantitative easing based money-printing interference. This selfenforcing vicious circle of tautology and no-exit strategy has a tendency to persist.

The "chronic excess of savings over investment" is not the cause of secular stagnation, but its consequence. Like a fever is characterized by high temperatures and hot foreheads - yet is not caused by them. What causes the imbalance? Why are savings so high and investments so low? Why should it be "chronic"? What causes the incentives to invest to be so low? What are the causes of the current awry situation? Causation itself is the missing link of the economic "rebels without a cause". Without a cause, there is no diagnosis; without diagnosis, there can be no cure. Stating the obvious should not become the "new obvious". It is not enough for the Fed to "carefully monitor the numbers, and adjust the policy accordingly". Without a credible theory of causation, there can be no understanding of what is happening and why.

\section{Interest rates}

Interest rates are the natural measure of the value of money. When interest rates lose their signaling capability, when they are artificially kept low, economic and investment decision making loses its key benchmark and goes haywire; i.e. both investment and saving money become critically uncertain and find their way into speculation and gambling, further distorting the economic conditions. There can be no true economy without the true and reliably signaling interest rates. 
Traditionally, when interests rates went up, people started saving instead of spending and companies lowered their investment rate. When interest rates went down, people shifted to spending and companies to investing. This cyclical balancing of the interests of producers and consumers, with the help of interest rates, was going on for millennia.

Now the Fed is holding the interest rates at zero (some Swiss "banks" even at negative) levels and yet: savings are growing and investments are declining - the very opposite of normal or rational behavior. Saving when money is real cheap and not investing when it is even cheaper. This is a true misalignment and there is no point in keeping stressing it. The only interesting questions are: why should it be chronic? What causes it? Why should will to invest be so low? Why should there be such a dearth of ideas to invest in? Why is the propensity to speculate and gamble so high? How and when is the secular stagnation going to end? Or will it ever end? Without answering such questions we can have no useful economics, although there still are bound to remain useful economies.

\section{Evolution of human economy}

In order to answer any of the questions at all, we have to turn to the evolutionary economics, instead of consulting current, static, context-free and optimal allocation-based version of governmental interference as an economic driver.

All natural socio-economic systems undergo evolution. Historically, such evolutionary changes were extremely protracted and time consuming. Many generations traversed significant transformations without ever being able to see the "big picture" of their own evolutionary history. Even today some still have a genetic-cultural tendency to emphasize the shortterm changes and disregard the long-term ones. Yet, the increasing masses of thinkers and doers are becoming aware of the rapid acceleration of change in the $21^{\text {st }}$ century. Even within one generation we are now likely to witness and be affected by qualitative changes in technology, ways of production and consumption, transformations of human institutions, advances in knowledge, skills and expertise, as well as rapid disappearance of the old ones. It is now the time to turn our attention to long-term causes and implications of widespread losses of the old and equally widening emergence and march of the new and even of the very new. The times have changed for humanity.
There are many layers of socio-economic evolution, not always properly reflected in the description and explanations of social sciences. The reality of action is now changing faster than its descriptions.

One such important layer is the evolution of the forms of capital. We can recognize four basic forms of capital: natural, built, human and social. Their relative contribution, value and importance is forever changing, forming an eternal cycle of interdependent co-evolutionary sub-cycles. Let us define and describe the four capital forms:

$\mathbf{N}$ Natural capital. This represents a large portfolio of natural resources and mineral wealth, including soil, water, air, fossil and volcanic forms of metals, minerals and chemicals. Into the portfolio $\mathrm{N}$ also belong current biomass and organisms. All components of $\mathrm{N}$ are subject to renewable or non-renewable mining and degradation, as well as renewal, cultivation, re-cyclation and re-use.

B Built capital. All built and constructed physical assets and infrastructure: from buildings, roads and dams all the way to technology and logistical and communication means. B represents national "hardware" of sorts.

H Human capital. All investments into humans: their knowledge, skills and capabilities necessary for the effective use of natural (N) and built (B) capital. These investments include education, culture, behavior, health, nutrition, potential, talent, motivation and effort. Human capital represents national "software" (know-how) and "brainware" (know-what and know-why).

S Social capital. This is the enabling organizational infrastructure: institutions, corporations, civil associations, cultural, collective, individual and family values, institutions of trust, protection and legal justice, as well as traditions, respect and capabilities for participation, cooperation, belonging and usefulness.

In Fig. 1 we have displayed the evolutionary cycle from autonomous $\mathrm{N}$, leading to (especially with the emergence of humans) to $\mathrm{B}$ and its co-evolution with $\mathrm{N}$. Then emerges $\mathrm{H}$ and co-evolves with $\mathrm{N}$ and $\mathrm{B}$. Finally, the emergence of $\mathrm{S}$ completes the cycle towards $\mathrm{N}$, while interacting with and mutually affecting and interacting with $\mathrm{B}$ and $\mathrm{H}$ as well. The current result is the natural and dominant hyper cycle of co-evolutions of N, B, H and S.

The main purpose of this digression into the nature of our past is displayed at the top of Fig. 1, as an accompanying transformational chain of $(\mathrm{H})$ A-I-S-G sectors of dominant human activity and employment, ranging from pre-historical hunting and 


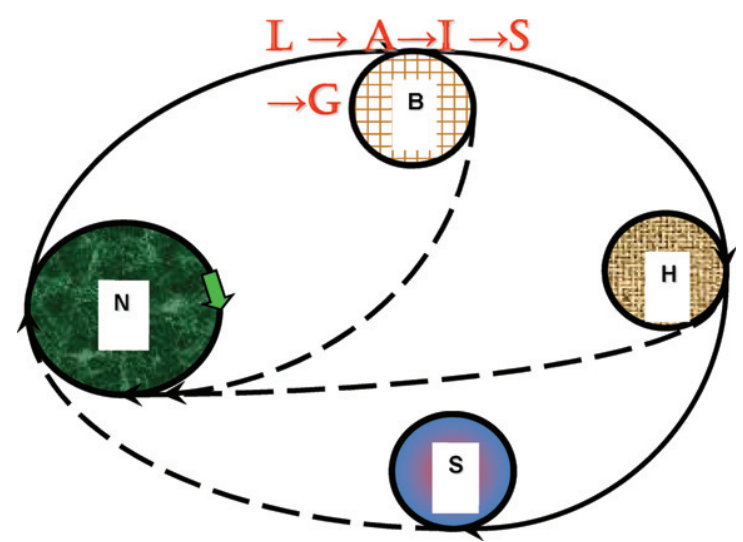

Fig. 1. Evolution and co-evolution of N, B, H and S forms of capital.

gathering, through agriculture and industry, until current service and governmental employment. While the primeval hunting and gathering did not yet have significant economic dimensions, the remaining four sectors represent four fundamental economic sectors of activities. Humans can economically engage in food production (A), production of things (I), provision of services (S) and consumption of governmental services $(G)$. There is no known economic activity which would not belong into one of these categories (or sectors).

It is virtually self evident that with the continuous (and accelerating) striving for productivity improvement and competitiveness enhancement, supported with the progress in labor-saving and employment reducing technology, knowledge, materials, organization and institutions, there is a point where the employment capacities of all four sectors become curtailed and even declining. Even though clearly unique in world history, we are now facing that very point.

\section{Productivity growth impacts}

In Fig. 2 we display the evolution of the employment share of the workforce in the four economic sectors. Sector's percentage share of employment changes in dependency on sector's productivity growth rate. Agriculture has emerged and vanished (as a source of new employment). Today only $1 / 2$ per cent of the workforce is employed in the US agriculture - the most productive sector of the economy. Then industry had emerged, peaked and contracted. Services have emerged and started rapid contracting - all due to secular productivity growth rates. A last sector has emerged: government, welfare

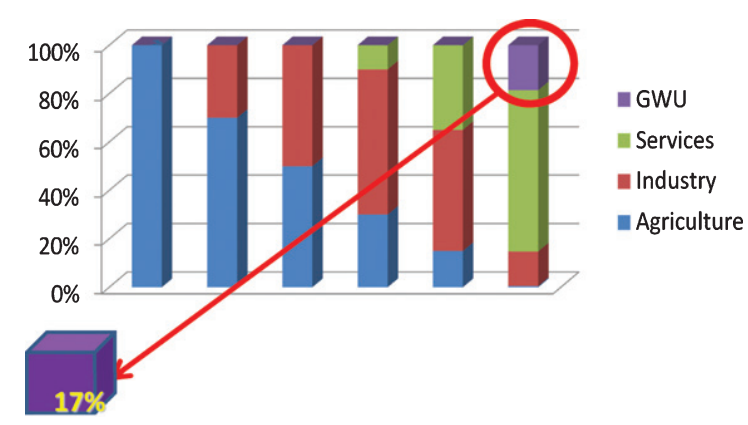

Fig. 2. Sector employment dynamics due to productivity growth rates (USA).

and unemployment (GWU), based on taxes-financed consumption rather than added-value production, sheltered from market forces, consuming (via taxation) added value created in the three productive sectors. Creating jobs in the GWU sector is very limited because it can only be financed from taxation. Larger employment capacities of GWU are unsustainable because of the growing indebtedness.

\section{The four things humans do...}

The US economy has now become the most mature in terms of sectoral evolution. It has entered the stage - perhaps as the first economy, followed by Japan and $\mathrm{EU}$ - of declining employment in the service sector.

Accelerating productivity growth rates are dictated by global competition and human striving for better standards of living - they cannot be stopped at will. Slowly and imperceptibly, advanced economies are shifting towards sectors with lower added value, leading to lower incomes and wages and increased reliance on speculative bubbles and debt.

So, the US, Japan and EU are at the transforming cusp as thousands of years of sectoral development comes to a prolonged stagnation and stop. There are only four essential things humans can do economically: 1. Produce food, 2. Manufacture goods, 3. Provide services and 4. Do nothing. There is no new sector lurking in the offing: the sequence of qualitative transformations is coming to an end. Developing economies still have some time left, still have to industrialize, and some still have the services to expand. But the US economy is now the harbinger of the things to come, the role model for others to follow or reject, but hardly ignore. For the first time in history, at least one economy has reached the end of the old model (or paradigm) and is groping for the 
new ways of organizing its business, economy and society.

Human economic activity has therefore undergone at least four fundamental transformations:

1. From nomadic hunting and gathering $(\mathrm{H} / \mathrm{G})$ to localized agriculture

2. From localized agriculture (A) to internationalized industry

3. From international industry (I) to global services

4. From global services (S) to public sector (including government, welfare and unemployment, GWU)

\section{Basic dilemma and emerging metamorphosis}

Continued growth in productivity and competitiveness cannot shift from GUW to another (non-existing) productive sector. This dilemma of most advanced economies (USA, Japan, and EU) is displayed in Fig. 3.

In Fig. 3 we separate the last workforce bar of Fig. 2, in order to see the impact of productivity growth as it is in the US today.

All four sectors are subject to accelerated productivity growth rates, and thus declining employment share of the workforce, in the near future. The only expanding space of the workforce is the grey region "?" in Fig. 3, essentially reflecting the decline in overall workforce participation rate. This grey area is also the space of the new transformation: that's where those who left unemployment registers are starting new ventures and enterprises, and participating in regional economies.

This new "transformation" is different from all preceding sector transformations: it does not usher in a new sector but completes the secular cycle of localization $\longrightarrow$ globalization $\longrightarrow$ re-localization. A new economic paradigm is emerging, with a new structure, behavior, institutions and values. A more precise label would be Economic Metamorphosis. Metamorphosis is the outcome of a series of transformations, not dissimilar to a caterpillar-to-butterfly change of form, through the construction $\longrightarrow$ destruction $\longrightarrow$ reconstruction autopoietic selfproduction cycle.

Even when the recession ends, the metamorphosis of economic form shall continue, accelerate and expand. Less and less we shall be able to tell the difference. Pressures for increased productivity growth

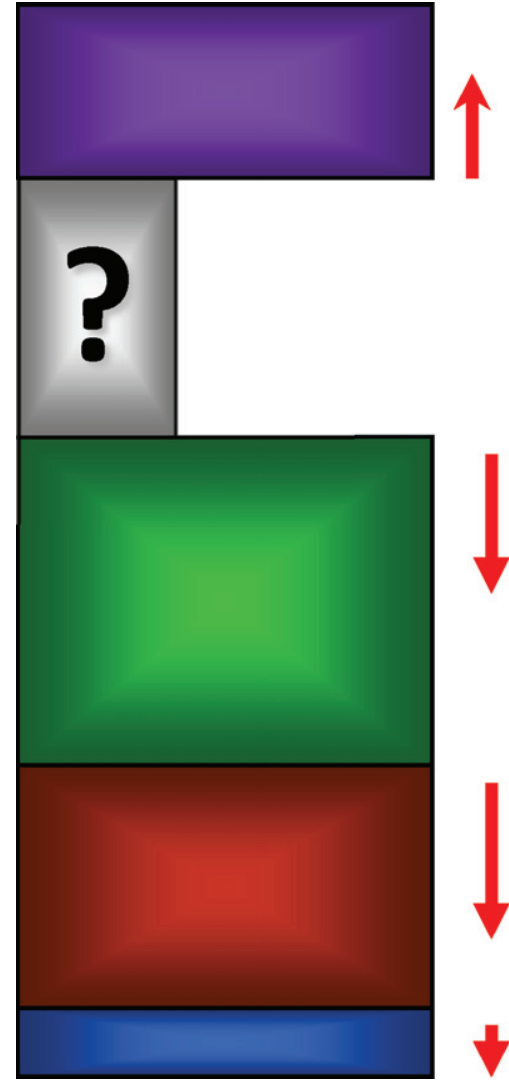

Fig. 3. The conditions for economic metamorphosis

rates, declining employment and workforce participation, as well as budget cuts shall grow unabated. Due to the massive automation, sector GDP can grow even under the conditions of declining employment. More than that: increasing the minimum wage, historically rather neutral with respect to employment, will now be readily replacing low-level jobs with ever cheaper and more abundant automation - along with millions of jobs being lost due to the still uninformed and aimless political processes. Obscuring the difference between cyclical crisis and the ongoing transformation (metamorphosis) is not without consequences: when true diagnosis is not attempted, and people do not know what is happening with their economy and why, all forms of contagious social unrest follow worldwide.

\section{Deglobalization}

Because there is no new productive sector to emerge, the market system seeks to reinstate its new balance through new modes of doing business. 
Deglobalization is taking place, supply chains are turning into demand chains, large economies are focusing on their internal markets, and outsourcing is followed by "back sourcing", returning activities back to the countries and locations of their origin. The original slogan of "Think globally, act locally," is being re-interpreted as exploiting global information and knowledge in local action, under local conditions and contexts.

While globalization refers to a restructuring of the initially distributed and localized world economy into spatially reorganized processes of production and consumption across national economies and political states on a global scale, in deglobalization, people move towards relocalization: the global experience and knowledge becoming embodied in local communities. So, the corso-ricorso of socio-economic transformation is properly captured by a triad Localization $\longrightarrow$ Globalization $\longrightarrow$ Relocalization.

The trend of deglobalization is turning much more significant during these years. The growth of worldwide GDP is now exceeding the overall growth of trade for the first time; foreign investment (Cross Border Capital Flows) is only $60 \%$ of their precrisis levels and has plunged to some 40 percent. World capital flows include loans and deposits, foreign investments, bonds and equities - all down in their cross-border segment. This means that the rate of globalization has reversed its momentum. Globalizers are still worried about 2014 being the year of irreversible decline. Improvement in the internal growth of U.S.A., EU, and Japan does not carry into external trade - these economies are starting to function as zero-sum.

With this transformation, an entirely new vocabulary is emerging in economics: in addition to deglobalization and relocalization, we also encounter glocalization (adjustment of products to local culture) and local community restoration (regional self-government and direct democracy). With relocalization, an entire new cycle of societal corsoricorso is brought forth. Local services, local production and local agriculture, based on distributed energy generation, additive manufacturing and vertical farming, are enhancing individual, community and regional autonomy through self-service, disintermediation and mass customization. Both requisite technologies and appropriate business models necessary for relocalization are already in place, forming a vital part of our daily business and life experience. This transformation and metamorphosis are well on their way.

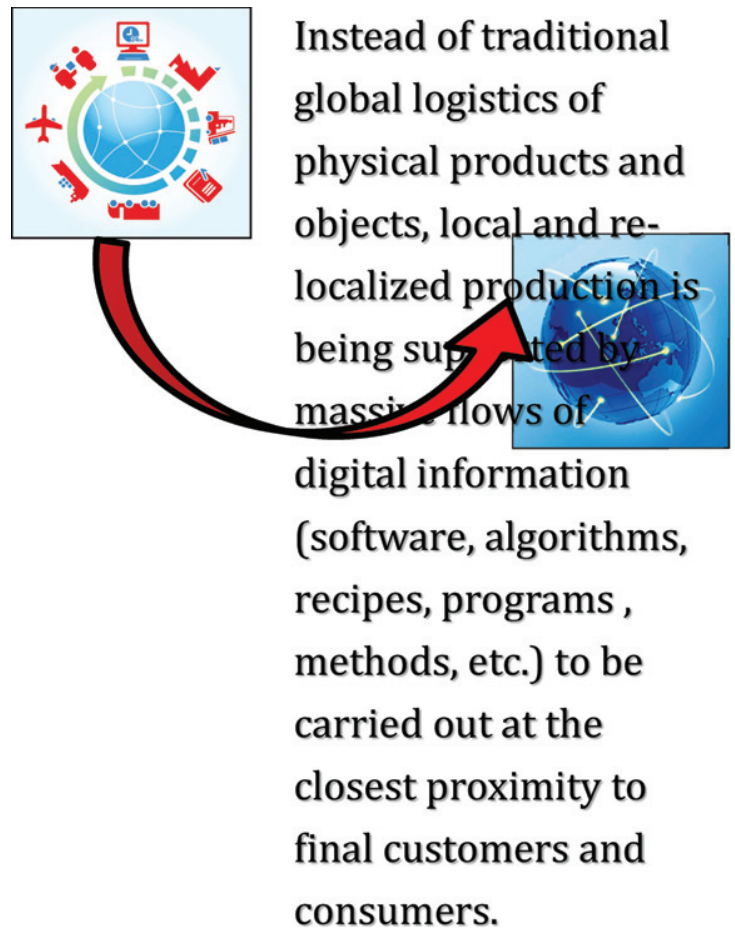

Fig. 4. At the speed of light ...

Re-localization and regionalization does not imply separation and isolation: just the opposite. The world will become even more interconnected and cooperative through effective sharing of information and digitized knowledge - at the speed of light.

\section{From information to knowledge}

Information can be downloaded from the entire world; knowledge is produced through local action. Every action takes place in a given context of time, place and culture. The ability to coordinate action - i.e. knowledge and experience, is maintained in the domain of mental and neuro-motoric reactions. The rules of coordination emerge through instinct, inner skills, external learning or expert reformulation. Knowledge is action; information is digital or analog description of action. The difference between action and its symbolic description is expanding (similar to the difference between what we say and what we do). All knowledge (action) is necessarily tacit (accessible through descriptions only, while all information is explicit (not easily transformed into action).

We are now going through deglobalization of action (localization and re-localization of global 
action), while strengthening globalization and quantity of information flows. Every action (knowledge) is local, every description of action (information) is global. We are entering the era of global information and local knowledge (we download cookbooks of the entire world, but the art of cooking emerges through local action only). We know what to do and how. To know about is not the same as to know how; to know why complements knowledge with wisdom. Information flies around the world at the speed of light, but products and the inventories are transported and shipped around slowly and dearly. It is now necessary to produce locally, at the closest proximity to customer (even by the customer itself - self-production and self-service).

\section{Foundation ZET}

The Age of Metamorphosis, characterized by local and regional autonomy, independence and self-reliance will be accompanied by The Age of Entrepreneurship, characterized by entrepreneurial activities of individuals, localities and regions. In order to help advancing the capabilities of companies and regions, an entrepreneurial foundation ZET (Zoom in Entrepreneurship and Technology) has been established.

Among the main purposes of ZET, which we can find the following:

1. The development of projects aimed at the renewal of national entrepreneurship, creating innovative business culture and the development of original products, services, and complex business models in all areas of business.

2. The development of regions via active cooperation of regional enterprises, local governments and universities with the aim of achieving their synergy, autonomy and independence.

3. The development of Czech enterprises and entrepreneurs in the area of complex systems of corporate governance, decision making and strategic thinking, in terms of the principles of the Bata Management System, i.e. autonomy and self-sufficiency in order to increase global and local competitiveness.

4. The development of schools and their educational programs in the areas of regional development, corporate management and effective self-government, rooted in the principles of the Bata Management System.
5. The development of Entrepreneurial university through the innovative strategy of the region, which is directly involved in the formation of new companies as the basic "carriers" and users of entrepreneurial knowledge. The network of entrepreneurial universities is directly involved in the generation of employment, knowledge and development of the region. Such universities not only teach, but also actively do business themselves and produce not only the graduates, but also the firms, in which the graduates remain active.

6. The development of students through the study of educational programs and practical realization of original world-class business plans.

The Foundation is registered in the Czech Republic, but through direct branches or collaborative associations with local groups, companies and institutions, the Foundation is building up its presence also in the USA, China, Japan, Singapore, India, Brazil and others. Its main mission can be characterized by an extension of the old Chinese proverb:

"Give a person a fish and he will eat for one day; teach people to fish and they will eat for a lifetime; provide a village with the means of sustainable fishing, herding and farming - and they will teach you how to live."

\section{Recent sources of the underlying theory}

Zeleny, M. (1997) Autopoiesis and Self-Sustainability in Economic Systems. Human Systems Management, 16(4): 251-262.

Zeleny, M. (2009) On the Essential Multidimensionality of an Economic Problem: Towards Tradeoffs-Free Economics. Czech Economic Review, 3(2): 154-175.

Zeleny, M. (2010) Machine/Organism Dichotomy of Free-Market Economics: Crisis or Transformation? Human Systems Management, 29(4): 191-204.

Zeleny, M. (2012) Crisis or Transformation: On the corso and ricorso of human systems," Human Systems Management, 31(1): 49-63.

\section{Earlier sources}

- "The Self-Service Society: A New Scenario of the Future", Planning Review, 7(1979) 3, pp. 3-7, 37-38. 
- "Towards a Self-Service Society", Human Systems Management, 1(1980) 1, pp. 1-3.

- "Socio-Economic Foundations of a Self-Service Society", in: Progress in Cybernetics and Systems Research, vol. 10, Hemisphere Publishing, Washington, D.C., 1982, pp. 127-132.

- "Self-Service Trends in the Society", in: Applied Systems and Cybernetics, Vol. 3, edited by G. E. Lasker, Pergamon Press, Elmsford, N.Y., 1981, pp. 1405-1411.

- "Self-Service Aspects of Health Maintenance: Assessment of Current Trends", Human Systems Management, 2(1981) 4, pp. 259-267. (With M. Kochen)
- "The Grand Reversal: On the Corso and Ricorso of Human Way of Life", World Futures, 27(1989), pp. 131-151.

- "Structural Recession in the U.S.A.", Human Systems Management, 11(1992)1, pp. 1-4.

- "Work and Leisure", in: IEBM Handbook on Human Resources Management, Thomson, London, 1997, pp. 333-339. Also: "Bata-System of Management," pp. 359-362.

- "Industrial Districts of Italy: Local-Network Economies in a Global-Market Web", Human Systems Management, 18(1999)2, pp. 65-68.

- "Genesis of the Worldwide Crisis", in: Atlas of Transformation, JRP Ringier, Zurich, 2010. 